\title{
EL CONTROL DE CONSTITUCIONALIDAD DE LOS AUTOS ACORDADOS Y LOS DERECHOS FUNDAMENTALES
}

\author{
Carol Delgado ${ }^{1}$
}

\section{INTRODUCCIÓN}

Los autos acordados constituyen cuerpos de normas generales y abstractas dictadas generalmente por los tribunales colegiados, con el objeto de imponer medidas o impartir instrucciones dirigidas a velar por el más expedito y eficaz funcionamiento del servicio judicial. ${ }^{2}$

Estos autos acordados, en cuanto a fuentes formales de derecho, como todas las restantes, quedan sometidos a la Constitución y la ley, en lo que atañe a sus prescripciones, por lo que la regulación que aborden, no podría incursionar en materias que el constituyente hubiera reservado al legislador.

No obstante ello, en el ejercicio de la superintendencia económica la Corte Suprema y otros tribunales superiores no sólo dictan autos acordados para el mejor cumplimiento de sus tareas, sino que para regular el modo en que ejercerán las acciones o recursos que el orden constitucional reconoce cuando el legislador no hubiere previsto el procedimiento con sujeción al cual sustanciarlas.

Entonces, se trata de cuerpos reglamentarios de orden procesal u orgánico que han debido dictarse ante la inacción del legislador que no ha cumplido el deber constitucional de proveer de un procedimiento justo y racional conforme al cual tramitar los recursos o acciones constitucionales, como así también el ejercicio de otras atribuciones privativas de los tribunales. ${ }^{3}$

$\mathrm{Al}$ respecto, la doctrina está conteste que los autos acordados no son fuente constitucionalmente idónea para regular el ejercicio de las acciones reconocidas en la Carta Fundamental.

\footnotetext{
${ }^{1}$ Abogada de la Contraloría General de la República. Magíster en Derecho Constitucional, Universidad de Talca.

2 Silva Bascuñan, Alejandro: Tratado de Derecho Constitucional, Tomo VIII, Ed. Jurídica de Chile, p. 156.

${ }^{3}$ Pfeffer Urquiaga, Emilio: “Autos acordados, Control de Constitucionalidad y Procedimiento", en ponencia presentada en el Seminario Académico: "Reflexiones sobre la Ley Orgánica Constitucional del Tribunal Constitucional y su Control de Constitucionalidad", Centro de Estudios Constitucionales, Universidad de Talca, Santiago, 21 y 22 de octubre de 2009.
} 
Dichas críticas, surgidas en torno a las reglas procedimentales en ellos contenidas, en especial las que se han dictado respecto del auto acordado que regula la sustanciación del recurso de protección, explica la nueva competencia asignada al Tribunal Constitucional, consignada en la reforma constitucional de 2005, que confió a este tribunal el control de constitucionalidad de los autos acordados dictados por los órganos jurisdiccionales que consigna el artículo 93 No 2 de la Carta Fundamental.

Lo anterior, tiene una gran trascendencia en relación a la protección en el ejercicio de los derechos fundamentales, de aquellas personas que se han visto afectadas por lo dispuesto en el respectivo auto acordado, sobre todo, respecto del significado y extensión de la expresión "derechos fundamentales" a que alude la norma.

Por ello, se ofrece en este trabajo un análisis de la situación actual del control de constitucionalidad de los autos acordados y la protección de los derechos fundamentales, tras la reforma constitucional de 2005 en Chile.

\section{ANTECEDENTES DEL CONTROL DE CONSTITUCIONALIDAD DE LOS AUTOS ACORDADOS}

Con motivo de que algunas reglas contenidas en autos acordados dictados por la Corte Suprema para regular la sustanciación del recurso de protección, contemplado en el artículo 20 de la Carta de 1980, impusieron requisitos adicionales a los establecidos en ésta para admitir su tramitación -especialmente aquel referido a la fijación de un plazo para su interposición-, surgieron numerosas críticas fundadas en la eventual inconstitucionalidad de dichos autos acordados por excederse en su competencia.

Como consecuencia de dicha polémica y frente a la inconstitucionalidad de que podían adolecer, surgieron voces llamando, por una parte, a que en general todos los autos acordados de esa índole fuesen sometidos al control de constitucionalidad del Tribunal Constitucional, y, por otra parte, a que el relacionado específicamente con la tramitación del recurso de protección fuese establecido por ley.

Teniendo en cuenta lo expuesto, al estudiarse en la Comisión de Constitución del Senado, la reforma constitucional que se traducirá en la Ley No 20.050, el entonces ministro del Tribunal Constitucional don Eugenio Valenzuela Somarriva, manifestando la conveniencia de establecer un sistema de control concentrado de constitucionalidad, propuso confiarle al Tribunal Constitucional el "control preventivo y obligatorio de los autos acordados de la Corte Suprema, de las Cortes de Apelaciones y del Tribunal Calificador de Elecciones", soste- 
niendo al efecto que "la Corte Suprema se esforzará siempre porque sus autos acordados se ajusten a la Constitución, pero se discute si aquel que regule la acción de protección está o no ajustado a la Carta Fundamental”. Por su parte, el informe que envió la Corte Suprema a la mencionada Comisión rechazó la idea, expresando que "los autos acordados son resoluciones de carácter y efectos internos que dicta esa Corte (Suprema), generalmente relativas al más expedito y eficaz funcionamiento de los tribunales ordinarios de justicia. A veces, en casos excepcionales, se producen vacíos normativos u omisiones legales básicamente de naturaleza procesal, y cuando ello ocurre, la Corte Suprema, para que los jueces puedan desempeñar en forma apropiada y conducente sus labores, dicta el auto acordado supletorio necesario, el que tiene vigencia sólo hasta cuando se legisle al respecto. No le pareció, entonces, necesario ni conveniente someter los autos acordados a control de constitucionalidad, atendida su naturaleza y finalidad".

En definitiva, el primer informe de la Comisión recogió la sugerencia del mencionado ministro del Tribunal Constitucional, por cuanto le confió el control preventivo de los autos acordados dictados tanto por la Corte Suprema como por las Cortes de Apelaciones y el Tribunal Constitucional de Elecciones, siempre que versasen sobre materias constitucionales esos órganos jurisdiccionales enviarían al Tribunal Constitucional el respectivo auto acordado dentro de los cinco días siguientes a su aprobación.

El proyecto fue despachado por el Senado, en el primer trámite, incluyendo el precepto en los términos ya referidos; en segundo trámite, la Cámara de Diputados decidió confiar al Tribunal la resolución de las cuestiones de constitucionalidad de los autos acordados ya dictados, emanados de los mismos órganos jurisdiccionales a que se refería el precepto aprobado por el Senado, estableciendo que el requerimiento lo podía presentar el Presidente de la República, cualquiera de las Cámaras, diez de sus miembros o "toda persona que sea parte en juicio o con gestión pendiente ante un tribunal ordinario o especial, cuando sea afectada por lo dispuesto en el respectivo auto acordado"; dentro de las observaciones presentadas por el Presidente de la República al proyecto de reforma constitucional aprobadas por las Cámaras, se propuso agregar a la norma ya despachada, el control de constitucionalidad, también represivo y eventual, de las instrucciones generales del Ministerio Público, en cuyo caso debía presentar el requerimiento respectivo la persona afectada "desde la primera actuación del procedimiento penal"; en el informe del Senado recaído en las observaciones del Ejecutivo se deja constancia que la mayoría estuvo por acoger la observación presidencial; por último, la referida observación fue retirada luego por el Ejecutivo, con lo cual se eliminó del 
proyecto aprobado la facultad de conocer las cuestiones de constitucionalidad de las instrucciones generales del Ministerio Público. ${ }^{4}$

\section{LA PROTECCIÓN DE LOS DERECHOS FUNDAMENTALES Y EL CONTROL DE CONSTITUCIONALIDAD DE LOS AUTOS ACORDADOS}

\section{III.1. El poder de los Tribunales Superiores de Justicia para dictar autos acordados y los principios constitucionales}

Un sector claro de nuestra doctrina, que ha sido la que con mayor fuerza ha criticado la eventual inconstitucionalidad de los autos acordados por excederse en su competencia, sostiene que no hay un solo artículo en la Constitución que de manera explícita faculte a la Corte Suprema a dictar autos acordados. La única disposición que tiene relación con este punto es el artículo 82, inciso $1^{\circ}$, al disponer que ese alto tribunal tiene la superintendencia directiva, correccional y económica de todos los tribunales de la Nación. Por el contrario, otra doctrina sostiene que los autos acordados son la manifestación más importante de la superintendencia económica de la Corte Suprema (ya desde el estudio del proyecto de Ley Orgánica de Tribunales, en 1870, se había afirmado lo anterior y, ahora último, también lo hizo el Tribunal Constitucional (Rol No 783-07). ${ }^{5}$

Sin embargo, no hay tanta claridad a la hora de precisar los límites exactos de ese poder especial de los más altos tribunales de justicia y lamentablemente la ley no presta mayor auxilio. En otras palabras, las facultades económicas habilitan a la Corte Suprema para velar permanentemente por el orden interno del Poder Judicial, disponiendo medidas, tanto para el mejor y más expedito funcionamiento de los organismos y órganos pertenecientes al Poder Judicial, como para la actuación del personal de dependencia de todos ellos. ${ }^{6}$ Entonces, sólo se podría aseverar que los autos acordados reflejan el poder auto-organizativo doméstico con que cuenta cualquier órgano público o, en palabras del Tribunal Constitucional, se trata de una capacidad de "autorregulación" del funcionamiento de los tribunales.

\footnotetext{
${ }^{4}$ Silva Gallinato, María Pía: "Control de Constitucionalidad de los Autos Acordados", en Temas Actuales de Derecho Constitucional, Libro homenaje al profesor Mario Verdugo Marinkovic. Edit. Jurídica de Chile, año 2009, páginas 323-325.

${ }^{5}$ Soto KLoss, Eduardo: El recurso de Protección, Edit. Jurídica de Chile, año 1982, p. 230.

${ }^{6}$ Carvallo P., Manuel: "Validez de los Autos Acordados como normas reguladoras de procedimientos", en Memoria de Prueba, U. Católica de Valparaíso, Facultad de Ciencias Jurídicas y Sociales, año 1999, Valparaíso, p. 39.
} 
Ahora bien, a la hora de detallar el contenido exacto de la función económica, ninguna de las Constituciones de 1828, 1833, 1925 y 1980 se han pronunciado. ${ }^{7}$ Lo anterior, porque el Constituyente ha entendido desde siempre que el contenido detallado de las facultades económicas no es una materia de incidencia o de importancia para ser regulada a nivel constitucional, por ejemplo: establecimiento de horarios y medios o modos de atención al público, en general, y de los letrados, en particular; el nombramiento por el Poder Judicial de sus propios funcionarios y la facultad de concederles licencias; la calificación de dichos funcionarios; proponer al Presidente de la República las reformas necesarias a las leyes procesales o los temas sobre los que es necesario legislar, entre otras. ${ }^{8}$

En este contexto, entonces cabría preguntarse ¿̇dónde está la norma constitucional -dentro del texto escrito de la Constitución- que habilite a la Corte Suprema a regular, a través de los autos acordados, la forma y modo como se ejercen y resguardan los derechos fundamentales de las personas? La respuesta resulta sencilla: en ninguna parte. En otras palabras, la Corte Suprema no fue invitada por el Constituyente a dictar autos acordados, especialmente los referidos a los artículos 20 y 19 No 7, letra i), sin embargo, lo hizo atribuyéndose una competencia que estaba entregada al legislador.?

En efecto, ninguna magistratura, ninguna persona ni grupo de personas pueden atribuirse, ni aun a pretexto de circunstancias extraordinarias, otra autoridad o derechos que los que expresamente se les hayan conferido en virtud de la Constitución o las leyes (art. $7^{\circ}$, inc. 2ª CPR); lo que, respecto de los órganos públicos, se encuentra indisolublemente unido con el deber que pesa en ellos de someter su acción a la Constitución y a las normas dictadas conforme a ella (art. 6º CPR). Como se aprecia, la vulneración del artículo $7^{\circ}$, inciso $2^{\circ}$, lleva necesariamente unida la infracción del artículo $6^{\circ}$, inciso $1^{\circ}$.

Es más, los autos acordados de la Corte Suprema que regulan el recurso de protección de las garantías constitucionales y la acción de indemnización por error judicial, no tan sólo contienen normas de estricto carácter adjetivo, es decir, disposiciones que regulan sobre procesos, sino que también normas sustantivas que inciden en la vigencia de los derechos de las personas. En efecto, aquí se regula

\footnotetext{
${ }^{7}$ Carvallo P., Manuel: Op. cit., p. 18.

${ }^{8}$ Moraga Klenner, Claudio: "Auto Acordados como fuentes del Derecho Público", en Trigésima séptimas jornadas de Derecho Público. Fuentes de Derecho Público, Valparaíso 8 y 9 de noviembre de 2007, Facultad de Derecho Universidad Católica de Valparaíso, p. 3.

${ }^{9}$ ANDRADes R., Eduardo: "Algunos comentarios al nuevo auto acordado sobre tramitación del recurso de protección”, en Revista Chilena de Derecho, Actas XXIX Jornadas de Derecho Público, número especial, 1998, Facultada de Derecho Universidad Católica de Chile, p. 121.
} 
sobre tramitación de acciones, diligencias y actuaciones procesales, pero, también, sobre sanciones de caducidad por vencimiento de plazos establecidos por la propia Corte Suprema. Este solo hecho constituye una afectación de derechos fundamentales no autorizada por el Constituyente, además de contravenir el espíritu de la Constitución, puesto que mientras al Poder Legislativo se le prohíbe delegar en el Presidente de la República materias comprendidas dentro de los derechos fundamentales, el tercer Poder del Estado asume dicha potestad y atribución como propia, mutando su naturaleza que, de ser receptor del ordenamiento jurídico, pasa a ser productor neto de normas de aplicación general. ${ }^{10}$

Finalmente, es bueno considerar que los autos acordados, a la luz de la Constitución de 1980, pueden tener limitada aplicación, de orden interno de los tribunales, para un mejor aprovechamiento de sus recursos humanos y materiales, y que jamás podrán afectar los derechos humanos en su esencia, ni imponer condiciones o requisitos que impidan su libre ejercicio, pues si la Constitución prohíbe al legislador hacerlo, con mayor razón está impedida cualquier norma jurídica de rango inferior, cualquiera sea el órgano del cual emane, así sea la Corte Suprema o el Tribunal Constitucional. ${ }^{11}$

No obstante todo lo expuesto, cierta doctrina nacional, al tiempo que reconoce que los autos acordados han excedido su ámbito de aplicación, sustentan justificaciones que no pueden conciliarse con el inciso $2^{\circ}$ del artículo $7^{\circ}$. Los fines superiores que invocan a este respecto, entre otros son: la poca flexibilidad en el proceso de formación de la ley; la incapacidad de los órganos legislativos para regular materias de sumo compleja; la búsqueda de utilidad y eficacia práctica y el principio de inexcusabilidad de los tribunales de justicia; los que, sin embargo, no pueden superar la norma constitucional que prohíbe arrogarse atribuciones que no hayan sido expresamente conferidas por la Constitución y las leyes. Por otra parte, tampoco es posible justificar nuestra realidad constitucional actual, a partir de la que se vivió durante la Constitución de 1925: en ésta no era obligatorio que las regulaciones procesales se establecieran necesariamente por ley ni existía la garantía del debido proceso legal, que sí se contienen en la Constitución de 1980 (artículos 19 No 3, y 63). ${ }^{12}$

Ahora bien, el poder de los tribunales superiores de justicia para dictar autos acordados, tras la reforma constitucional del año 2005, cambia, ya que la propia

\footnotetext{
${ }^{10}$ Moraga Klenner, Claudio: Op. cit., p. 3.

${ }^{11}$ Bruna C., Guillermo: "Los autos acordados de la Corte Suprema sobre recurso de protección", en Revista Chilena de Derecho, Actas XXIX Jornadas de Derecho Público, número especial, 1998, Facultada de Derecho Universidad Católica de Chile, p. 133.

${ }^{12}$ BRuna C., Guillermo: Op. cit., p. 133.
} 
Constitución valida la producción normativa de los autos acordados a nivel de Cortes de Apelaciones, Corte Suprema y Tribunal Calificador de Elecciones. El Tribunal Constitucional toma nota de esto cuando, en su sentencia Rol No 783, de 2007, en la que por primera vez tiene lugar y se acoge una acción constitucional por afectación de derechos fundamentales ante el Tribunal Constitucional en contra de un auto acordado, señalando que: "Si el artículo 93 No 2 de la Carta Fundamental otorga a esta Magistratura competencia para revisar la constitucionalidad de estas normas, es evidente que valida esta competencia”.

Sin embargo, al analizar la fuente de la facultad para dictar autos acordados, el Tribunal Constitucional elige un camino de dudosa constitucionalidad. Ello, en cuanto señala que "desde siempre" se ha entendido que la capacidad para dictar autos acordados proviene de las facultades económicas que competen, en primer lugar, a la Corte Suprema, aunque también a las Cortes de Apelaciones. Ello, se ve reforzado con lo señalado en el cierre del considerando $24^{\circ}$ que señala: "El reducido ámbito regulatorio que la requirente pretende asignarle a los autos acordados no se aviene con la tradición de las importantes cuestiones que, desde la época de la Colonia, la Real Audiencia primero y luego la Corte Suprema vienen regulando por medio de autos acordados".

Si bien el fallo señala en su considerando $25^{\circ}$ que los autos acordados no pueden regular materias que el constituyente ha reservado al legislador, en el mismo considerando, la sentencia reza como sigue: "En aspectos de funcionamiento en que el legislador no ha establecido normas o que expresamente la Constitución no la ha reservado a éste, el propio órgano judicial puede autorregularse”.

En este sentido, sostiene cierta doctrina que resulta cuestionable el giro de nuestro Tribunal Constitucional hacia fuentes no jurídicas, o al menos no jurídico-positivas del ordenamiento jurídico público de nuestro país. Lo anterior, por cuanto la incorporación de la idea de tradición, en un sistema jurídico de corte racional normativo basado, al menos en el ordenamiento jurídico público, en el derecho positivo, no permitiría mantener el apego al inciso segundo del artículo $7^{\circ}$ de la Constitución, el que, de lo contrario, empezaría a resquebrajarse peligrosamente. ${ }^{13}$

Por tanto, a la luz de la sentencia en comento y en consideración a que, como se señaló, tiene el mérito de ser la única que ha acogido la acción de inaplicabilidad en contra de un auto acordado por afectación de derechos fundamentales, se debería reforzar la premisa de que la fuente de la facultad de las Cortes de Ape-

\footnotetext{
${ }^{13}$ Aldunate Lizama, Eduardo: Jurisprudencia Constitucional 2006-2008. Estudio Selectivo. Edit. LegalPublishing, año 2009, páginas 69-71.
} 
laciones para dictar autos acordados se encuentra en el artículo 93 de la Carta, y no en otros preceptos.

\section{III.2. Alcance de la protección de los derechos fundamentales en el control de constitucionalidad de los autos acordados}

Se muestra indispensable, en primer lugar, transcribir el No 2 del artículo 93 de la Constitución, según el cual es atribución del Tribunal Constitucional: "Resolver sobre las cuestiones de constitucionalidad de los autos acordados dictados por la Corte Suprema, las Cortes de Apelaciones y el Tribunal Calificador de Elecciones".

De acuerdo con lo dispuesto en el inciso tercero del artículo 93, pueden presentar el requerimiento respectivo tanto "el Presidente de la República, cualquiera de las Cámaras o 10 de sus miembros", como "toda persona que sea parte en juicio o gestión pendiente ante un tribunal ordinario especial, desde la primera actuación del procedimiento penal, cuando sea afectada en el ejercicio de sus derechos fundamentales por lo dispuesto en el respectivo auto acordado".

Los órganos habilitados para presentar la cuestión de constitucionalidad pueden actuar en todo momento, invocando la vulneración de cualquier norma constitucional, ya referida a una regla orgánica, dogmática o relacional, que consista en la inconstitucionalidad en un vicio de forma o de fondo.

Mientras tanto, las personas que deseen reclamar en contra de un auto acordado sólo pueden hacerlo cumpliendo los requisitos indicados en el precepto.

En efecto, por una parte, sólo puede interponer el requerimiento quien se vea afectado "en el ejercicio de sus derechos fundamentales por lo dispuesto en el respectivo auto acordado", y, por otra, el interesado además debe ser parte en una gestión judicial pendiente de fallo ante un tribunal. Así, por ejemplo, quien se vea afectado por un auto acordado que establezca un plazo muy reducido para ejercer un recurso, antes de pedir el pronunciamiento del Tribunal Constitucional, deberá hacerse parte en una gestión judicial, sin que la Carta le permita acudir a él a través de una acción pública.

La persona interesada, por otra parte, ha de cumplir con una serie de exigencias que, en muchos aspectos, resultan idénticas a las que se imponen para presentar un requerimiento de inaplicabilidad (art. 93 No 6) y que son las siguientes:

a) Debe ser parte en un juicio o gestión, o sea, debe haberse apersonado en la gestión o juicio por tener un interés en él.

b) El juicio o gestión debe encontrarse pendiente, es decir, no debe haber sido resuelto ni estar ejecutoriado, debiendo interponerse la acción en cualquier oportunidad procesal en que se considere que el auto acordado pueda lesionar los derechos del recurrente. 
c) El juicio o gestión debe seguirse ante un tribunal ordinario o especial, con lo cual se sigue también de cerca la redacción que el constituyente dio al artículo 93 No 6.

d) El requerimiento puede ser presentado por toda persona que sea "parte en juicio o gestión pendiente ante un tribunal ordinario o especial, desde la primera actuación del procedimiento penal".

e) Cumpliendo con los presupuestos ya estudiados, la solicitud es formulada por la persona "cuando sea afectada en el ejercicio de sus derechos fundamentales por lo dispuesto en el respectivo auto acordado".

La exigencia de procesabilidad de que la persona "sea afectada en el ejercicio de sus derechos fundamentales por lo dispuesto en el respectivo auto acordado" alude a que la prescripción normativa en él contenida tenga la amplitud de lesionar el "ejercicio" de derechos fundamentales, pero ello no implica que el Tribunal Constitucional sea llamado a ejercer un control concreto, pues nos se exige, para declarar la inconstitucionalidad de todo o parte de sus normas, que su aplicación produzca resultados contrarios a la Constitución Política a la parte en el juicio o gestión pendiente. ${ }^{14}$

$\mathrm{Al}$ respecto, bastaría la sola circunstancia de que el texto del auto acordado contenga reglas que afecten el ejercicio de derechos fundamentales, para que el Tribunal Constitucional declare la inconstitucionalidad de dichos preceptos, por lo cual no es necesario que se hayan aplicado en el hecho esas normas para que se produzca la afectación.

Se requiere así apreciar la norma del auto acordado en abstracto, confrontando su mero contenido con el de los derechos fundamentales, para llegar a la conclusión de que su preceptiva, por la sola forma en que está consagrada, pugna con algún derecho fundamental, produciendo así la inconstitucionalidad. Así lo ha entendido el propio Tribunal Constitucional cuando sostuvo, en el considerando 7 o del fallo Rol No 783, de 31 de agosto de 2007, que a él corresponde examinar "la constitucionalidad de aquellos preceptos del Auto Acordado que tengan la aptitud de afectar el ejercicio de derechos fundamentales del requirente".

Por otra parte, de la norma transcrita se desprende que su intérprete habrá de determinar qué entiende por "derechos fundamentales", para decidir si incluye dentro de esa categoría jurídica únicamente a los asegurados en el capítulo III de la Constitución, o si comprende del mismo modo a los demás reconocidos a lo largo de todo el texto constitucional, o si se refiere también a los derechos esenciales que emanan de la naturaleza humana a que alude el artículo $5^{\circ}$, se encuentren o no

${ }^{14}$ Pfeffer Urquiaga, Emilio: Op. cit., p. 8. 
asegurados expresamente en la Carta, incluyendo, por cierto, a los de ese carácter reconocidos en los tratados ratificados por Chile y vigentes.

En este sentido, el concepto debería tener la mayor amplitud posible, por cuanto la acción que se concede a las personas afectadas por el auto acordado debe constituirse en una garantía realmente efectiva para lograr el resguardo del ejercicio de sus derechos, sin embargo, conviene resaltar que, no obstante la extensión que puede darse a los vocablos empleados, si se compara la nueva herramienta que se concede al afectado por un auto acordado con la que posee quien solicita la inaplicabilidad de un precepto legal, queda de manifiesto que esta última acción es más amplia, por cuanto puede fundarse en cualquier infracción a un precepto constitucional, sea éste constitutivo o no de un derecho fundamental. ${ }^{15}$

En este contexto, el fallo, ya mencionado, del Tribunal Constitucional, Rol No 783, de 2007, resulta histórico en las materias que venimos desarrollando, toda vez que es la primera vez que un auto acordado de tribunales superiores de justicia es controlado por un órgano ajeno a la superintendencia de la Corte Suprema y, al menos en una parte, declarado inconstitucional. Por otra parte, también es la primera vez que tiene lugar y se acoge una acción constitucional por afectación de derechos fundamentales ante el Tribunal Constitucional.

Es en este segundo aspecto es donde se desprenden del fallo una serie de consecuencias gravitantes para el tratamiento de los derechos fundamentales en nuestra Constitución, dándose por sentado que, a pesar de ser toda una innovación en nuestro lenguaje constitucional, la expresión "derechos fundamentales" que utiliza el artículo 93 inciso tercero de la Carta Fundamental es coincidente con el ámbito que cubren los derechos constitucionales del artículo 19 de la Carta.

En este fallo la expresión derechos fundamentales del artículo 93 inciso tercero de la Carta comprende al menos, y sin discusión, todo el contenido de su artículo 19, sin distinción de si la fórmula normativa se expresa en términos de derechos subjetivos o de deberes estatales; el concepto de afectación no se encuentra sometido a una exigencia de efectividad de la lesión, o principio de trascendencia, sino simplemente de la contradicción normativa con la Constitución, y que esta contradicción no se circunscribe a la infracción por parte del respectivo auto acordado de un precepto de derecho fundamental, sino que de cualquier precepto constitucional que entre en conexión con el razonamiento asociado al derecho fundamental invocado. ${ }^{16}$

${ }^{15}$ Silva Gallinato, María Pía: Op. cit., pp. 328-331.

${ }^{16}$ Aldunate Lizama, Eduardo: Op.cit., pp. 91-92. 


\section{CONCLUSIONES}

El mismo Tribunal Constitucional, al que se le ha otorgado el control de constitucionalidad de los autos acordados, en la materia que venimos tratando, ha sostenido que "un derecho es afectado en su esencia cuando se le priva de aquello que le es consustancial, de manera tal que deja de ser reconocible, y que impide el libre ejercicio, en aquellos casos en que el legislador lo somete a las exigencias que lo hacen irrealizable, lo entraban más allá de lo razonable o lo privan de tutela jurídica". ${ }^{17}$

En este sentido, creemos que los autos acordados que regulan la tramitación del recurso de protección de las garantías constitucionales y la acción de indemnización por error judicial, de los artículos 20 y 19, No 7, letra i) de nuestra Carta Fundamental, incurren precisamente en la situación referida por nuestro Tribunal Constitucional, siendo en estos casos aún más grave que el legislador no encause estas infracciones, sino que lo haga el Poder Judicial, encabezado por la Corte Suprema.

En efecto, los citados autos acordados vulneran en su esencia el derecho fundamental a ser indemnizado por error judicial y de aquéllos garantizados por el recurso de protección, limitando su libre ejercicio, puesto que en su texto supeditan la alegación a exigencias injustificadas, carentes de legitimidad constitucional, que no están establecidas en nuestra Constitución. Estas exigencias procedimentales vuelven excesivamente oneroso el ejercicio de los derechos fundamentales, haciéndolos irrealizables, e ilusorios en sus propósitos, desnaturalizándolos más allá de lo razonable, privándolos de resguardo efectivo, pudiendo eventualmente verse afectado el derecho de acceso a la jurisdicción y a la tutela judicial rápida y oportuna que vulnera nada menos que el derecho humano de acceso a la jurisdicción asegurado por el artículo $8^{\circ}$ de la $\mathrm{CADH}$ y el artículo 14 del PIDCP.

Ahora bien, desde la reforma señalada, existe una escasa jurisprudencia del Tribunal Constitucional recaída sobre la materia, sólo un fallo ha declarado, a la fecha, la inconstitucionalidad, en parte, de un auto acordado, por la afectación de derechos fundamentales. Sin embargo, dicha sentencia constituye un claro referente en la extensión de la expresión "derechos fundamentales", toda vez que alude a los asegurados en el Capítulo III de la Constitución, pero comprende, del mismo modo, los demás reconocidos a lo largo de todo el texto constitucional, sean implícitos o explícitos; los derechos esenciales que emanan de la naturaleza humana (artículo 50) y los reconocidos en tratados ratificados

${ }^{17}$ Sentencias del Tribunal Constitucional, Roles Nos. 283, 245 y 279. 
por Chile y vigentes, observándose en torno a esta facultad de la Magistratura Constitucional el real alcance de la noción "bloque de derechos", cuya defensa, cuando sean lesionados por un auto acordado, el Tribunal Constitucional está llamado a cautelar. ${ }^{18}$

Lo anterior, redunda en una verdadera protección al derecho a la tutela judicial efectiva, acceso a la justicia y debido proceso, consagrados tanto en nuestra Carta como en la CADH y el PIDCP, lo que implica, en definitiva, garantizar dichos derechos en nuestra jurisdicción, sin que aquellos que resulten afectados en su ejercicio por un auto acordado, fundados en la vulneración del artículo 25 de la $\mathrm{CADH}$, deban necesariamente recurrir ante la Corte Interamericana de Derechos Humanos para encontrar su debida protección, como ocurrió en el caso "Marcel Claude y Otros contra Chile, Caso Número 12.108”.

En consecuencia, el control de constitucionalidad de los autos acordados, introducido con la reforma de 2005, en particular, aquellos que regulan el procedimiento para hacer valer derechos fundamentales, representa un importante avance para resguardar la supremacía constitucional en nuestro ordenamiento jurídico, configurando de esta forma una jurisdicción constitucional plena y unitaria radicada en el Tribunal Constitucional.

\section{Bibliografía}

Aldunate Lizama, Eduardo: Jurisprudencia Constitucional 2006-2008. Estudio Selectivo. Editorial LegalPublishing, año 2009.

Carvallo P., Manuel: "Validez de los Autos Acordados como normas reguladoras de procedimientos", en Memoria de Prueba, U. Católica de Valparaíso, Facultad de Ciencias Jurídicas y Sociales, año 1999, Valparaíso.

Moraga Klenner, Claudio: Autos Acordados como fuentes del Derecho Público, en Trigésima séptimas jornadas de Derecho Público. Fuentes de Derecho Público, Valparaíso 8 y 9 de noviembre de 2007, Facultad de Derecho Universidad Católica de Valparaíso.

Pfeffer Urquiaga, Emilio: "Autos acordados, Control de Constitucionalidad y Procedimiento", en ponencia presentada en el Seminario Académico: "Reflexiones sobre la Ley Orgánica Constitucional del Tribunal Constitucional y su Control de Constitucionalidad", Centro de Estudios Constitucionales, Universidad de Talca, Santiago, 21 y 22 de octubre de 2009.

Revista Chilena de Derecho, Actas XXIX Jornadas de Derecho Público, número especial, 1998, Facultad de Derecho Universidad Católica de Chile.

${ }^{18}$ Pfeffer Urquiaga, Emilio. Op. cit., p. 8. 
Silva Bascuñán, Alejandro: Tratado de Derecho Constitucional, Tomo VIII, Ed. Jurídica de Chile.

Silva Gallinato, María Pía: "Control de Constitucionalidad de los Autos Acordados”, en Temas Actuales de Derecho Constitucional, Libro homenaje al profesor Mario Verdugo Marinkovic. Edit. Jurídica de Chile, año 2009. 
